\title{
1 Fine scale plant community assessment in coastal meadows using UAV based 2 multispectral data
}

Villoslada Peciña, M. ${ }^{(1)}$, Bergamo, T.F. ${ }^{(1)}$, Ward, R.D. ${ }^{(1,2)}$, Burnside, N.G. ${ }^{(2)}$, Joyce, C.B..$^{(2)}$, Bunce, R.G.H. ${ }^{(1)}$ Sepp, K. ${ }^{(1)}$

1) Institute of Agriculture and Environmental Sciences, Estonian University of Life Sciences, Kreutzwaldi 13 5, EE-51014 Tartu, Estonia.

2) Centre for Aquatic Environments, School of the Environment and Technology, University of Brighton, Cockcroft Building, Moulsecoomb, Brighton, BN2 4GJ, United Kingdom

Corresponding author: Miguel Villoslada

mpecina@emu.ee

Kreutzwaldi 5, room 2c18, Tartu, 51014, Estonia

Highlights:

- $\quad$ Plant communities in coastal wetlands are at risk due to the impacts of global change

- $\quad$ Knowing the distribution of plant communities is essential for nature conservation

- $\quad$ Communities distribution maps were produced using a UAV-based multispectral sensor

- $\quad$ The Random Forest classifier yielded the highest classification accuracy

- $\quad$ Species diversity and aboveground biomass affect the classification performance

\section{ABSTRACT}

Coastal meadows worldwide are subjected to habitat degradation due to abandonment, intensification and the impacts of global change. In order to protect and restore these habitats and ensure the supply of valuable ecosystem services, it is necessary to know the extent and location of plant communities in coastal meadows. In this study, five plant communities were mapped at very high resolution in three different study sites in West Estonia. A fixed wing UAV was used to obtain multispectral images and derive a set of vegetation indices. Two different image classification techniques were used to cluster the vegetation indices maps and produce plant community distribution maps. The highest classification accuracy was obtained using a Random Forest classifier and 13 vegetation indices. Additionally, the spectral characteristics of the training samples were correlated with aboveground biomass and species diversity. Both biomass and species diversity were positively correlated with the spectral diversity of training samples and are thus likely to have an effect on the classification accuracy. The results of this study highlight the need to utilize a wide array of vegetation indices and assess the spectral characteristics of training samples in order to obtain high classification accuracies and understand the nature of misclassification errors. The resulting maps provide a solid foundation for global change impact assessment and habitat management and restoration in coastal meadows.

\section{KEYWORDS}

Coastal plant communities; UAV; vegetation indices; Random Forests; unsupervised classification 


\section{INTRODUCTION}

Biodiversity loss is a worldwide concern due to impacts from a variety of anthropogenic factors (Cardinale et al., 2012), and climate and land-use change are principal threats to vegetated coastal ecosystems and their supporting biodiversity (IPCC, 2013; Newbold et al. 2016). These threats include sea level rise, increasing storminess, changes in salinity (Ward et al. 2016b) and changes to management regimes, particularly for coastal plant communities (Clausen et al., 2013). In the Baltic Sea Region, Boreal Baltic coastal meadows are European priority habitats (EU Habitats Directive, 1992) resulting from continuous, low-intensity management, in the form of grazing and mowing (Paal, 1998). These grasslands support characteristic plant species and provide a habitat for a diversity of migratory and breeding bird species (Söderström et al. 2001) as well as a variety of plant species on the edge of their ranges (Paal, 1998). They also provide a wide range of ecosystem services including: fodder for cattle, carbon storage, habitat for pollinators, habitat for breeding and migratory birds, erosion control, and flood regulation (Leito et al., 2014; Villoslada et al., 2019)

In spite of their ecological importance, coastal meadows have been subjected to habitat degradation in the form of agricultural intensification in many areas and abandonment in others (Henle et al., 2008) and will likely be impacted by global change (Ward et al., 2016b). Whilst efforts have been made in some regions to halt this trend there is limited data available as to the current location and extent of the plant communities in many areas, and as a result there is little underlying information to support nature protection, restoration and management strategies.

In these coastal ecosystems, the provision of ecosystem services and resilience to environmental stressors including climate change are largely dependent on plant community type. In this regard, communities can be used as an indicator that can highlight environmental gradients (Ellenberg, 1979; Diekmann, 2003; Berg et al., 2012; Ward et al., 2013; 2016a) and can also be used to elucidate management status, disturbance or abandonment (Burnside et al., 2007; Brotherton \& Joyce, 2015) and the impacts of management regimes and intensity (Joyce, 2014; Joyce et al., 2016). Plant community classification is a well-established tool in ecology (Tansley, 1920; Mueller-Dombois \& Ellenberg, 1974; Crawley, 1997; Burnside et al., 2007) and plants are often used as indicators due to the fact that they are relatively simple to survey and can give a powerful overview of the ecosystem. Moreover, in the frame of ecosystem services (ES) science and practice, plant communities can be regarded as Service Providing Units (SPUs), understood as spatially explicit units within which ES are provided (Burkhard \& Maes, 2017). SPUs constitute an essential first step to obtain robust ecosystem service supply models because they reflect the underlying ecosystem functions and their spatially explicit nature (Crossman et al., 2013). In this respect, recent methodological developments for mapping and assessment of ecosystem functions and services require very detailed spatial and thematic scales to model the complex dynamics of ecosystem service supply (Zulian et al., 2018). However, data concerning the location and extent of plant communities over large scales is often costly and time consuming to acquire. This problem has been in part addressed through the increased use of GIS and remotely sensed data (Jensen, 2007).

With the advent and rapid development of GIS software and the large amount of remotely sensed data available, these tools have been increasingly used for predictive plant community mapping (Burnside $\&$ Waite, 2011). Among the wide range of remote sensing techniques and platforms, there are many studies that use passive multispectral remotely sensed data to identify plant communities (Townsend \& Walsh, 2001; Brown et al., 2006; Balzarolo et al., 2009; Berni et al., 2009; Hamada et al., 2011; Strong et al., 2017). These studies used a methodology based on identifying specific reflectance values in different wavelengths of distinct vegetation by performing some form of classification, either unsupervised or supervised (Jones \& Vaughn, 2010). 
Satellite imagery has proven useful for automated or semi-automated vegetation mapping at a variety of scales, from regional level and low spatial resolution (Armitage et al., 2015) to community-level and high spatial resolution (Davidson et al., 2016). However, the sometimes coarse spatial resolution of these products render them impracticable for detailed plant community mapping, particularly within grasslands due to the fine scale pattern of communities (Rocchini et al., 2015). On the contrary, the availability and use of Unmanned Aerial Vehicles (UAVs) has undergone an exponential increase during the last decade (Baena et al., 2018). UAVs equipped with consumer grade digital cameras (Rasmussen et al., 2016), multispectral sensors (Candiago et al., 2015), hyperspectral sensors (Aasen et al., 2015) and thermal sensors (Turner et al., 2018) have been used in fields such as ecology, forestry, nature conservation and precision agriculture (Adão et al., 2017; Veettil et al., 2019), providing a much more detailed spatial resolution, in most cases down to the centimetre-scale. At the same time, the increasing amount of remotely sensed data produced with different satellite platforms and UAVs poses a challenge in terms of data processing and classification (Adão et al., 2017). Unsupervised and supervised classification algorithms are therefore a crucial tool to achieve interpretable results.

Unsupervised classification techniques group pixels according to their similarity in feature distance using a variety of different algorithms. Unsupervised classification does not require information on the spectral signatures of the objects under study. Instead, unsupervised classification methods cluster multidimensional datasets into relatively homogeneous classes of similar spectral signatures (Duda \& Canty, 2002). A wide array of unsupervised algorithms have been used in diverse applications, including automated mapping of tree species diversity (Schäfer et al, 2016), individual plant species mapping (Everitt et al, 2015) and environmental stratifications (Villoslada et al, 2016). However, a major drawback to this methodology is that the classes do not necessarily relate to different plant community classes on the ground, although the method does provide a good overview of spectral differences over the whole dataset (Jones \& Vaughn, 2010).

Supervised classification on the other hand, uses training sample areas to direct the classification process. Training sample areas can relate to plant communities or habitat data and are used to classify across the image (Hamada et al., 2011). These training pixels can be used to provide an accurate prediction of the location of different plant communities. A lot of attention has been directed towards the number of training samples and the size of training polygons (Chen \& Stow, 2002). However, the spectral characteristics of training samples may also have an effect on the classification performance. According to the Spectral Variation Hypothesis, the spectral variability of remotely sensed images is defined as the spatial variability of the remotely sensed signal within a given area and directly related to plant community type and species diversity (Rochinni et al, 2004). Previous studies (Oldeland et al, 2010; Rochinni et al., 2010b; Medina et al., 2013; Cavender-Bares et al., 2017), have assessed the relationship between ecological diversity at different scales and the spectral properties of the ecosystems under study. At the field/local scale, remote sensing has been proposed as a tool to estimate environmental heterogeneity and species diversity (Rochinni et al, 2010a). Grassland morphological characteristics, including biomass production, are also likely to affect spectral reflectance (Schweiger et al., 2018). Although spectral heterogeneity shows promising results in the fields of biodiversity monitoring and habitat management, it should also be accounted for in relation to the characteristics and quality of spectral training samples used in supervised algorithms. In order to adequately reveal the effects of species diversity on the spectral variability of the studied plant communities and its impact on classification, a pixel-based classification algorithm was preferred over an object-based image analysis classifier (OBIA). OBIA uses a set of features beyond pixel spectral information, namely shape, texture and context (Liu \& Xia, 2010). Although OBIA is considered to be a superior classification technique (Blaschke, 2010), the effects of shape, texture and context on the 
classification performance may interfere with the spectral variability analysis and was therefore discarded.

Among the wide spectrum of classifiers, the Random Forest machine learning classifier (Breiman, 2001) has been broadly used in recent years to extract information from multispectral, hyperspectral, radar, LiDAR and thermal imagery (Belgiu \& Drăguţ, 2016) as a powerful and efficient classification technique. Random Forest (RF) is an ensemble learning technique that has higher accuracy and is less impacted by the effects of noise compared to other machine learning algorithms that use single classifiers (Dietterich, 2000). This machine learning technique presents many advantages for remote sensing as: it runs efficiently on large databases; it estimates what variables are important in the classification; and it can deal with the nonlinearity of variables (Breiman, 2001; Gislason et al., 2006). Random Forest is based on decision trees, which enable the simultaneous classification of features based on a set of training samples and determination of the best performing explanatory variables (a bagging approach) (Lu \& He, 2017).

Despite its great potential and recent progress, the use of UAVs and classification algorithms for mapping grassland plant communities has received little attention in the scientific literature. Some studies have utilized different sensors and statistical algorithms to automatically map grassland communities, from consumer grade cameras (Gonçalves et al., 2015; Lu \& He, 2017) to multispectral sensors (Strong et al., 2017). In addition, UAVs have been used to estimate aboveground biomass production in grasslands (Wang et al., 2017).

In order to address the lack of knowledge and data on the location, spatial configuration and extent of plant communities in coastal meadows, the aim of this study was to assess the potential of UAVs and multispectral cameras for classifying and fine scale mapping of plant communities in coastal meadows. The objectives were to: (1) derive a wide range of vegetation indices from multispectral images and assess their capacity to differentiate between five plant community types in coastal meadows; (2) assess the capacity of supervised and unsupervised classification methods to differentiate between five plant community types and compare the results in a spatially explicit manner; (3) assess the spectral characteristics of training samples in relation to plant community composition and aboveground biomass.

\section{MATERIALS AND METHODS}

\subsection{STUDY SITES}

Estonia is located in the Baltic region between Latvia, Russia and Finland, in the border between the Boreal and Nemoral zones (Metzger et al., 2005). Despite its relatively small size $\left(45228 \mathrm{~km}^{2}\right)$ Estonia exhibits a high geological, morphological, and climatic diversity (Arold, 2005) and a long coastline of $3794 \mathrm{~km}$ due to the abundant bays, peninsulas, islands and islets (Ward, 2012).

Among the various coastal habitats in Estonia, coastal meadows (classified as Boreal Baltic coastal meadows according to Annex I of the Habitats Directive) occur in sheltered bays and coastlines and are characterised by low relief, often not exceeding a maximum elevation of $2 \mathrm{~m}$ above mean sea level (Ward et al., 2016b). Baltic coastal meadow landscapes typically consist of coastal wet grasslands, with swamp vegetation on the seaward edge, and scrub vegetation on the landward side. Baltic coastal meadows are formed and maintained by isostatic uplift/sediment accretion (Ward et al., 2014) and regular management, usually in the form of low intensity grazing or mowing (Berg et al., 2012). This low intensity human intervention halts succession to coarser vegetation types such as scrub, woodland 
and reed swamp and promotes high species richness (Burnside et al., 2007). As a result of habitat degradation coastal meadows have undergone a considerable loss of area, from 28750 ha of managed meadows in the 1950s (EFN \& RDSFNC, 2001) to around 8000 ha in the 2000s (Ingerpuu \& Sarv, 2015).

This study was undertaken in the Silma Nature Reserve in West Estonia. The reserve covers an area of 4780 ha and encompasses around 560 ha of coastal meadow (Burnside et al., 2007). Landowners include both the state and private persons. Silma Nature Reserve was first designated as a protected area in 1998 due to its strategic location along European bird migratory routes (Ward, 2012). Within the Reserve, three coastal meadows were selected for the analysis: Tahu North, Tahu South and Kudani (Fig.1). The sites were chosen due to the representability of the plant communities they contain and the continuous management undertaken since the 1990s. The three sites are regularly grazed with densities of $0.4-1.3 \mathrm{Au} / \mathrm{ha}$ according to the data registered by the Estonian Agricultural Registers and Information Board and the Silma Nature Protection Area Management Plan (Keskkonnaamet, 2017).

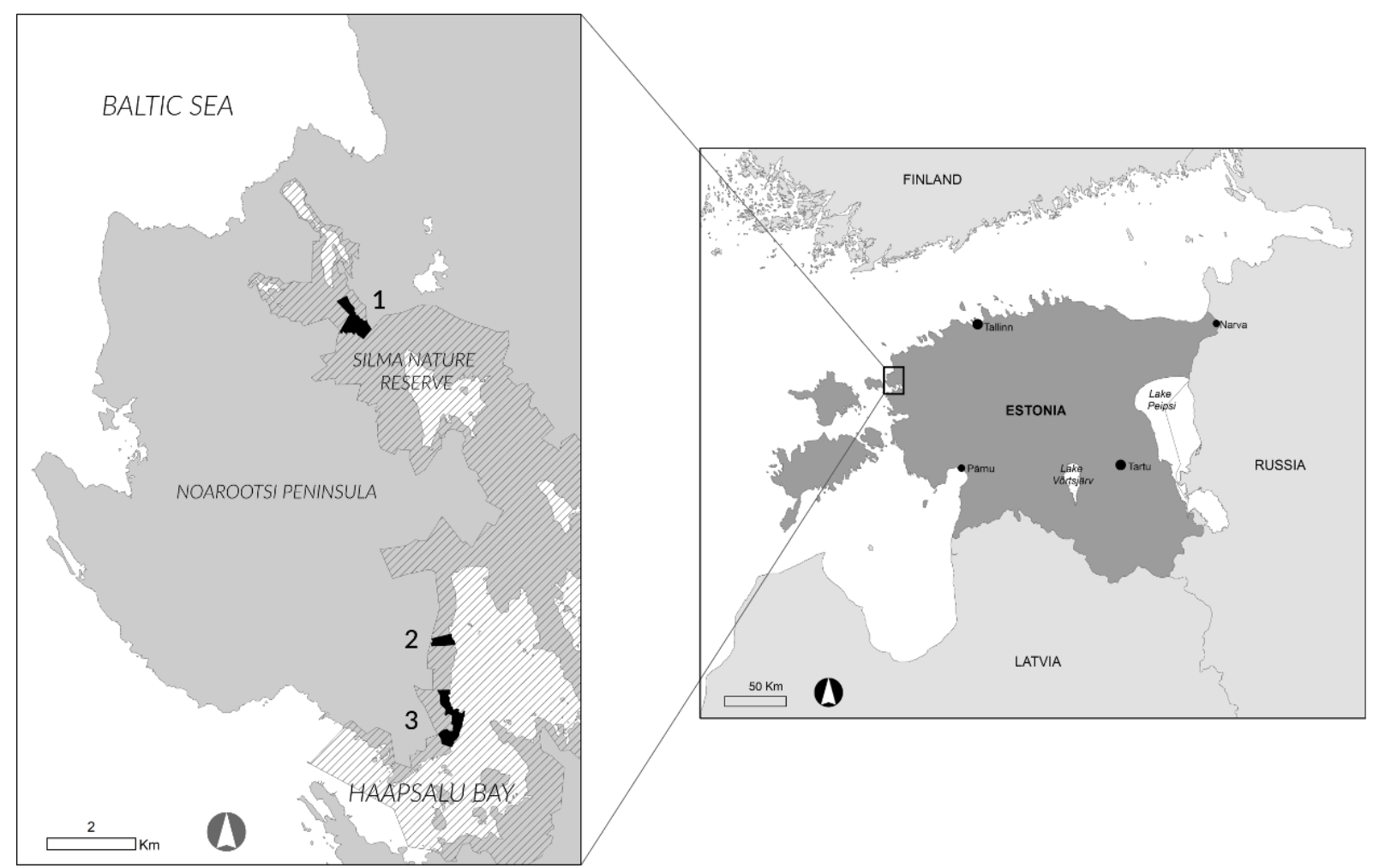

Fig. 1. Location of the study sites within the Silma Nature Reserve in West Estonia: (1) Kudani, (2) Tahu North, (3) Tahu South.

The vegetation at the study sites has been previously categorized into seven plant communities according the phytosociological classification developed by Burnside et al. (2007): Reed swamp (RS), Clubrush swamp (CS), lower shore meadow (LS), upper shore meadow (US), open pioneer (OP), tall grass (TG) and Scrub and developing Woodland (SW). Because of their peripheral occurrence in coastal meadows, the present study excludes CS and SW from the analysis. Table 1 contains a summary of the indicator species of the selected plant communities.

Table 1: Indicator species of selected plant communities. Adapted from Ward et al. (2016b).

\begin{tabular}{ll}
\hline Community & Key Species \\
\hline Reed Swamp (RS) & Phragmites australis
\end{tabular}


Lower Shore (LS) Juncus gerardii, Plantago maritima

Upper Shore (US) Festuca rubra, Leontodon autumnalis

Open Pioneer (OP) Salicornia europaea, Suaeda maritima

Tall Grass (TG) Elytrigia repens, Festuca arundinacea

\subsection{DATA COLLECTION}

202

203

204

205

206

207

208

209

210

211

212

213

214

215

\subsubsection{Plant community field sampling}

Field sampling was undertaken in July 2018 over a 1 week period. Plant communities were identified based on the phytosociological key developed for Baltic coastal wetlands (Table 1; Burnside et al., 2007).

In total, $1401 \mathrm{~m}^{2}$ quadrats were located using a stratified random approach (ten quadrats per community type in three sites) (Ward et al., 2016b). Within the quadrats, plants with an area coverage of $5 \%$ or more were recorded (Rodwell, 1995), as well as the cover of bare ground and litter. In the Open Pioneer community all plants were recorded as a result of the low cover of all species and predominance of bare ground.

$X, Y$ and $Z$ coordinates were recorded within all quadrats using a Sokkia GSR2700 ISX dGPS. Points were recorded in the corners and centre of all quadrats, five points per quadrat (Ward et al., 2013).

At Kudani, Lower Shore, Upper Shore, Open Pioneer and Tall Grass, plant communities were recorded. At Tahu North, Reed Swamp, Lower Shore, Upper Shore and Open Pioneer were recorded. And at Tahu South, Reed Swamp, Lower Shore, Upper Shore and Open Pioneer were recorded (Fig. 2). These were selected based on the plant communities that occurred in each site.

Additionally, aboveground biomass samples were collected at each study site in order correlate communities' structure with the spectral characteristics of the sampling quadrats. A $30 \times 30 \mathrm{~cm}$ biomass sampling plot was randomly placed within each vegetation quadrat after the species cover had been recorded. Grass was cut at ground level and samples were subsequently dried at $80^{\circ} \mathrm{C}$ for $48 \mathrm{~h}$ and weighed. Reed Swamp was excluded from the biomass analysis due to logistical constraints.
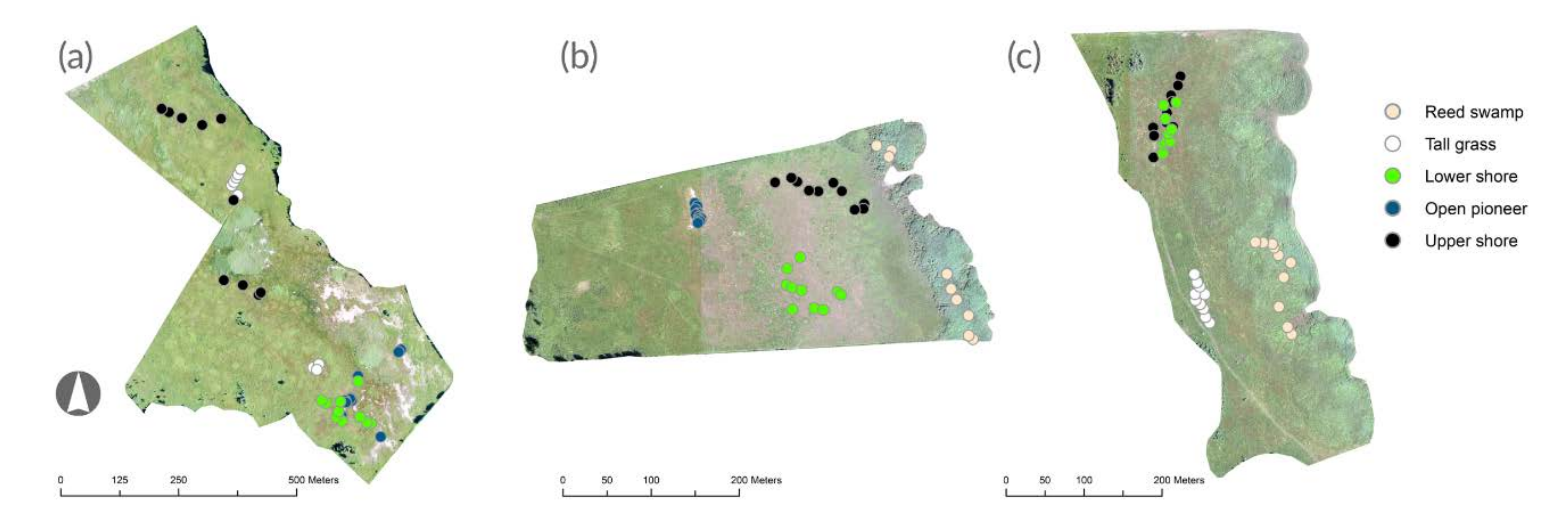
Fig. 2. Location of the sampling quadrats within the three study sites: (a) Kudani, (b) Tahu North, (c) Tahu South.

\subsubsection{Image acquisition}

Multispectral images were collected using a senseFly Ebee fixed wing UAV, with real-time kinematic (RTK) correction. The images were captured at a flight height of 120 metres, with a $10 \mathrm{~cm}$ pixel resolution. A Parrot Sequoia 1.2 megapixel monochromatic multi-spectral sensor was used to collect four distinct spectral bands: Green (530-570 nm), red (640-680 nm), red edge (730-740 nm) and near infrared $(770-810 \mathrm{~nm})$. Prior to each flight, an Airinov radiometric calibration target was used to capture calibration images for subsequent radiometric correction of the multispectral images. The images were captured during a total of five separate flights over the three coastal meadow sites covering an overall flight area of 61.4 ha.

Eleven ground control points (GCPs) were recorded using a Sokkia GSR2700 ISX dGPS for each flight in order to assess the geopositioning accuracy of the multispectral images (Strong et al. 2017).

\subsection{IMAGE PROCESSING AND ANALYSIS}

A total of 7615 images were pre-processed in eMotion $3^{\circledR}$. RINEX observation and navigation files were obtained from the ESTPOS Estonian GNSS-RTK permanent stations network (Eesti Maa-amet) for the post-processed kinematic (PPK) corrections of the images in eMotion $3^{\circledR}$. This process ensures a significant increase in the positional accuracy of the multispectral images (Tadrowski, 2014), from ca. $5 \mathrm{~m}$ to under $7 \mathrm{~cm}$ in the present study.

In order to obtain one multispectral orthomosaic per study site, the images were processed in Pix4D v.4.3.31 ${ }^{\circledast}$. The orthomosaics were subsequently clipped to the extent of the study sites in order to avoid the interference of the surrounding forest and scrub in the classification of the meadow vegetation.

The accuracy of the PPK corrections was assessed through Root Mean Square Error (RMSE) and Mean Absolute Error (MAE) calculations. RMSE and MAE were used to estimate the differences between the GCPs location in the images and the independent GCPs locations measured with the dGPS (Strong et al., 2017).

\subsection{VEGETATION INDICES}

A number of vegetation indices have been selected in the present study in order to determine their ability to differentiate plant community types. Satellite-derived vegetation indices have been used since the 1970s to gather information on vegetation health status, forest biomass production, agricultural production and crop monitoring and biodiversity conservation among other applications. The most commonly used vegetation index is the Normalized Difference Vegetation Index (NDVI) (Rouse et al., 1974). Originally conceived as an index to identify vegetated areas and assess their photosynthetic activity, the use of NDVI has been extended to a wide range of fields such as precision agriculture (Houberg \& McCabe, 2016), forestry (Robinson et al., 2017), fire damage assessment (Navarro et al., 2017) and habitat monitoring (Mafi-Gholami et al., 2019). Later, a wide variety of vegetation indices have been developed that partly overcome NDVI's limitations (Gu et al., 2013; Xue \& Su 2017). Among the indices selected for this study, some incorporate the red-edge region (680 $750 \mathrm{~nm}$ ) in their formulation, which is highly sensitive to leaf area index (LAI) and chlorophyll content 
and shows high potential for discerning vegetation characteristics and stress factors, as well as distinguishing plant community types (Delegido et al., 2013).

Table 2 contains the 13 indices selected for the study and the corresponding references. The selection of indices was undertaken based on their specific application in vegetation studies, as each individual index targets different aspects of vegetation condition, phenology, primary production and vegetation structure among others.

Table 2. List of vegetation indices selected in the present study. Vegetation indices were used to classify and map plant communities in the three coastal meadow sites.

\begin{tabular}{|c|c|c|}
\hline Vegetation index & Equation & Reference \\
\hline Normalized Difference Vegetation Index (NDVI) & $(N I R-R) /(N I R+R)$ & Rouse et al. (1974) \\
\hline Green Difference Vegetation Index (GDVI) & NIR-G & Sripada et al. (2006) \\
\hline Green Normalized Vegetation Index (GNDVI) & $(N I R-G) /(N I R+G)$ & Gitelson et al. (1996) \\
\hline Green Ratio Vegetation Index (GRVI) & $\mathrm{NIR} / \mathrm{G}$ & Sripada et al. (2006) \\
\hline $\begin{array}{l}\text { Green Infrared Percentage Vegetation Index } \\
\text { (GIPVI) }\end{array}$ & $N I R /(N I R+G)$ & Crippen (1990) \\
\hline Simple Ratio (SR) & $N I R / R$ & Jordan (1969) \\
\hline Green Difference Index (GDI) & $N I R-R+G$ & Gianelle and Vescovo (2007) \\
\hline Green Red Difference Index (GRDI) & $(G-R) /(G+R)$ & Gianelle and Vescovo (2007) \\
\hline $\begin{array}{l}\text { Red edge normalized difference vegetation } \\
\text { index (NDVIre) }\end{array}$ & $\begin{array}{l}\text { (NIR- } \\
\text { Rededge)/(NIR+Rededge) }\end{array}$ & Gitelson and Merzlyak (1994) \\
\hline Red edge simple ratio (SRre) & NIR/Rededge & Gitelson and Merzlyak (1994) \\
\hline $\begin{array}{l}\text { Red edge triangular vegetation index (core } \\
\text { only) (RTVIcore) }\end{array}$ & $\begin{array}{l}\text { 100(NIR-Rededge)- } \\
\text { 10(NIR-G) }\end{array}$ & Chen et al. (2010) \\
\hline MSRred edge & $\begin{array}{l}\text { (NIR/Rededge)- } \\
1 / \mathrm{V}(\mathrm{NIR} / \text { Rededge })+1\end{array}$ & Wu et al. (2008) \\
\hline Datt4 & $R / G *$ Rededge & Datt (1998) \\
\hline
\end{tabular}

\subsection{SUPERVISED PLANT COMMUNITY CLASSIFICATION}

278 In order to automatically classify and map plant communities in coastal meadows, a supervised 279 classifier algorithm was used to generate plant community maps for the study sites. The classification 280 of plant communities was performed in R (v3.5.1) using a Random Forest machine learning classifier. $\mathrm{R}$ packages used to perform $\mathrm{RF}$ were: 

imported into R (Bivand et al., 2015)

- $\quad$ raster package: enabling to read, manipulate, analyze and model the gridded spatial data (Hijmans \& van Etten, 2012).

- $\quad$ caret package: contains functions to streamline the model training process for complex regression and classification problems, and estimate model performance from a training dataset (Kuhn, 2012).

- $\quad$ randomForest package: for classification and regression based on a forest of decision trees using random inputs (Liaw \& Wiener, 2002).

- $\quad$ e1071 package: contains functions for latent class analysis and shortest path computation (Dimitriadou et al., 2006)

The Random Forest classifier was run with all the vegetation indices calculated in the previous step. All pixels falling within each of the 140 sampling quadrats were assigned to the corresponding plant community identified in the field and utilized as the training dataset. Additionally, plant community type was recorded in a supplementary batch of 140 quadrats as a validation dataset.

\subsection{UNSUPERVISED PLANT COMMUNITY CLASSIFICATION}

299

300

301

302

303

304

305

306

307

308

309

310

In order to explore the capabilities of different image classification techniques, the original dataset composed of 13 vegetation indices in 3 study sites was also subjected to an unsupervised classification algorithm.

The ISODATA clustering algorithm was chosen due to its ability to split large diffuse clusters and to merge small clusters whose centres are closer than a certain threshold (Memarsadeghi et al, 2007). The ISODATA clustering routine processes data in an iterative manner, based on minimum Euclidean distances between each pixel and the closest cluster in the multidimensional feature space of the selected spectral bands. Throughout the clustering process, each iteration recalculates clusters' means and reassigns pixels to the cluster with the closest mean value.

All study sites were clustered simultaneously to account for variations in light and atmospheric conditions and the number of clusters was set to five, in agreement with the five plant communities under study: Reed Swamp (RS), Lower Shore (LS), Upper Shore (US), Tall Grass (TG) and Open Pioneer (OP). Prior to the clustering process, a Principal Component Analysis (PCA) was run on the input variables. PCA has been widely use to extract uncorrelated variables from high dimensional multispectral data (Zabalza et al, 2014). The variables or components extracted in a PCA convey most of the spectral variability of the features under study and discard redundant information. Three combinations of input data were tested in ISODATA: (1) PCA on individual spectral bands, (2) PCA on the vegetation indices and (3) PCA on the vegetation indices and the spectral bands together. The first three components were used in all cases as input variables. Analyses were performed in ArcGIS 10.3.

\subsection{VALIDATION, CLASSIFICATION ACCURACY ASSESSMENT AND COMPARISONS BETWEEN MAPS}

A Fleiss Kappa statistic was used to assess the overall mapping accuracy of the different classification techniques (Ward et al., 2013). Based on the kappa statistic, the best performing algorithm was selected for in-depth analysis. Although kappa statistics reveal clustering and classification 
performances, additional tests are needed to explore in-depth classification accuracies for specific plant communities. Community-specific classification accuracies may reveal differences in spectral variability related to plant community composition and heterogeneity. An out-of-bag (OOB) estimate of error was thus used to assess the prediction error of the RF algorithm for individual plant communities (Gislason et al., 2006). In studies characterized by very high dimensionality, it is crucial to estimate the importance of each predictive variable in classifying the data in order to determine the variables performance. In order to detect the predictive power of the input variables within the RF algorithm, the Mean Decrease in Accuracy (MDA) and Mean Decreased Gini (MDG) for individual vegetation indices across all RF trees was analysed (Han et al., 2016). The Gini index is a measure of the homogeneity and purity of nodes and leaves. Each time a variable is used to split a node in the RF algorithm, the Gini index estimates the probability of a randomly chosen variable being wrongly classified. By excluding one variable from the classification process, RF estimates the MDG. A higher MDG indicates a higher variable importance in correctly splitting data in nodes across all trees (Rodriguez-Galiano et al., 2012). RF also calculates the MDA by randomly permuting the values of a certain variable in the $\mathrm{OOB}$ samples and subsequently recalculating the overall classification accuracy of the model (Rodriguez-Galiano et al., 2012).

Beyond simple kappa-based comparisons, spatial comparisons between land cover maps have been suggested as a tool to locate and quantify areas of land cover allocation disagreement (Gómez \& Montero, 2011). Detecting the spatial patterns of areas of disagreement may help identify classification uncertainties associated with spectrally complex areas or transitional plant communities. A spatial overlay was performed between the RF map and the map resulting from the best performing ISODATA cluster. In addition, the statistics $K_{\text {location }}$ (Pontius, 2000; Pontius, 2002) and Khisto (Hagen, 2002) were computed in order to provide an in-depth assessment of differences in the location and the histogram shape of plant communities in all three locations. Khisto accounts for the similarity/dissimilarity in the quantity of pixels belonging to the same category in two maps by comparing the frequency of categories in both maps. When the frequency of categories in two maps is equal, $K_{\text {histo }}=1$. $K_{\text {location }}$ compares the location of categories at the pixel level between two maps. When two categories lie at identical locations, $K_{\text {location }}=1$. The overall Kappa is computed as the product of $K_{\text {location }}$ and $K_{\text {histo. }}$

The kappa comparisons between the selected maps were performed in Map Comparison Kit (Visser and De Nijs, 2006).

\subsection{RELATIONSHIP BETWEEN SPECIES COMPOSITION, ABOVEGROUND BIOMASS AND SPECTRAL SIGNATURE.}

The methodology developed for this study characterizes within-sample spectral heterogeneity in relation to species diversity and biomass in order to assess the impact on the classification accuracy of the RF algorithm. In order to reduce the dimensionality of the spectral dataset, the spectral heterogeneity was calculated as the standard deviation (SD) of the first principal component of the individual bands. Species diversity was assessed using the Shannon index $\left(H^{\prime}\right)$ for species abundance:

$H^{\prime}=-\sum_{i=1}^{S} p_{i} \ln \left(p_{i}\right)$

\section{Where}

$S=$ total number of species in the sampling plot

$\mathrm{I}=$ the $\mathrm{i}^{\text {th }}$ species 
$\mathrm{P}=$ proportion of individuals of one particular species divided by the total number of individuals in the

367 sampling plot.

368 The Shannon index highlights the functional characteristics of the most abundant species (Rochinni et al, 2010a) and is likely to be less affected by the presence of rare species than species richness. This represents an adequate proxy for plant species composition in relation to spectral diversity.

A loess procedure (Cleveland et al., 1988) was applied to assess relationships between spectral diversity and species diversity and aboveground biomass. Loess is a locally weighted regression model that fits a function of the independent variable locally and in a moving fashion through a smoothing process. The purpose of this analysis was to explore the spectral nature of training samples rather than building a predictive model for species diversity and biomass. In this regard, loess offers a suitable visualization procedure. Loess analysis was executed in $\mathrm{R}$.

\section{RESULTS}

3793.1 Comparison of classification models

The Fleiss' kappa classification accuracy for each method is shown in table 3 and the maps obtained from different classification methods are shown in fig. 3. The overall classification accuracy was highest for the Random Forest algorithm with 13 vegetation indices as input variables, with a Fleiss kappa coefficient of 0.89 . The PCA on the 13 vegetation indices plus the four individual bands improved the classification accuracy of the unsupervised ISODATA algorithm from 0.31 (PCA on spectral bands) and 0.43 (PCA on vegetation indices) to 0.58 .

Table 3: Classification accuracy results for four different classification methods. A Fleiss' kappa coefficient was used to determine the level of agreement between expected and observed plant community types.

\begin{tabular}{ll}
\hline Classification method & Fleiss' kappa \\
\hline Random Forest with vegetation indices & 0.89 \\
ISODATA clustering with PCA on spectral bands & 0.31 \\
ISODATA clustering with PCA on vegetation indices & 0.43 \\
ISODATA clustering with PCA on vegetation indices and spectral bands & 0.58
\end{tabular}



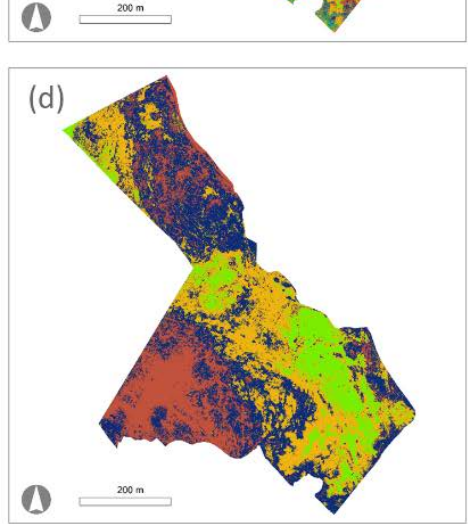

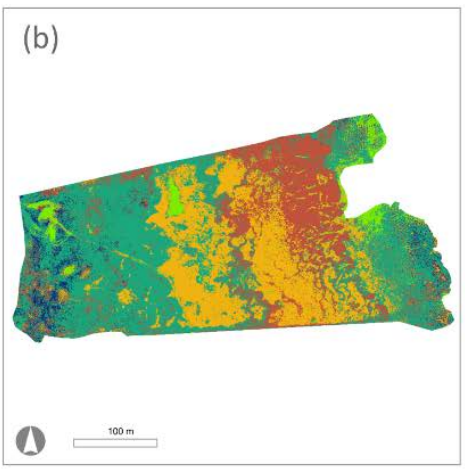

(e)

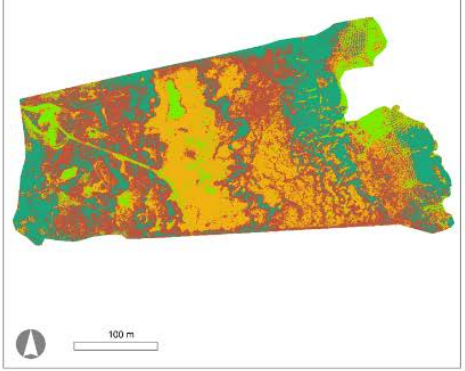

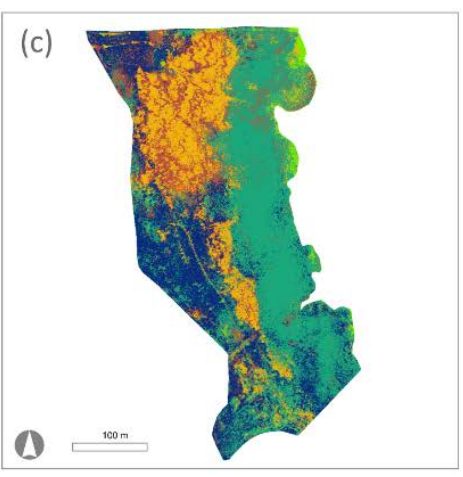

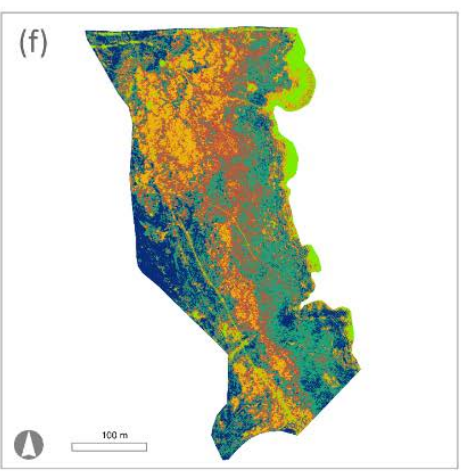

393

Fig. 3. Classification results for Random Forest with vegetation indices in Kudani (a), Tahu N (b), Tahu $\mathrm{S}$ (c) and for ISODATA clustering with PCA on vegetation indices and spectral bands in Kudani (d), Tahu N (e) and Tahu S (f). US: Upper Shore, LS: Lower Shore, OP: Open Pioneer, RS: Reed Swamp, TG: Tall Grass.

The comparison between the RF algorithm map and ISODATA clustering (PCA on vegetation indices and spectral bands) map yielded low levels of agreement (table 4). Tahu $\mathrm{N}$ shows the lowest values for overall Kappa (0.21) and $\mathrm{K}_{\text {location }}(0.31)$, whereas Kudani shows the lowest levels of $\mathrm{K}_{\text {histo }}(0.57)$.

Table 4. Overall kappa, $K_{\text {location }}$ and $K_{\text {histo }}$ results for the comparison between Random Forest and ISODATA maps. Kappa comparisons were performed individually for each study site.

\begin{tabular}{llll}
\hline Community & Kudani & Tahu N & Tahu S \\
\hline Kappa & 0.29 & 0.21 & 0.29 \\
KLocation & 0.51 & 0.31 & 0.39 \\
KHisto & 0.57 & 0.67 & 0.75 \\
\hline
\end{tabular}

Fig. 4 provides a visual interpretation of areas of agreement and disagreement between both classifications and an overview of classification disagreements per community type. The highest levels of agreement reflected by overall kappa and $\mathrm{K}_{\text {location }}$ and $\mathrm{K}_{\text {histo }}$ are reached in OP and LS respectively. RS and US show very low values of $\mathrm{K}_{\text {location }}$ and moderate values of $\mathrm{K}_{\text {histo }}$ in Tahu $\mathrm{N}$, indicating a certain degree of swapped classification between both communities, which can also be observed in fig 3 . 

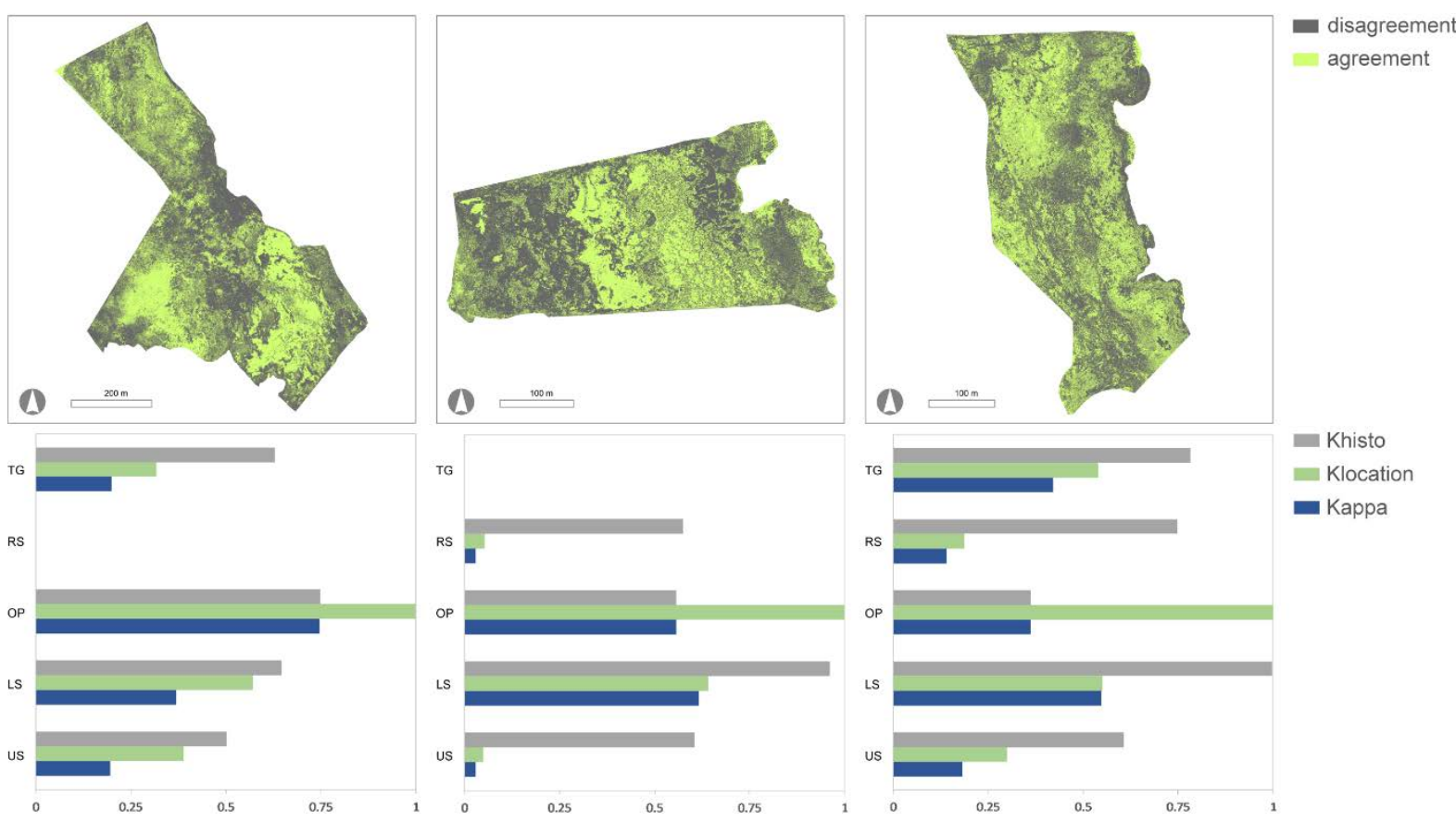

Fig 4. Areas of classification disagreement between RF and ISODATA and overall Kappa, $\mathrm{K}_{\text {location }}$ and $\mathrm{K}_{\text {histo }}$ values disaggregated per study site and community type.

\subsection{Random Forests accuracy assessment}

The performance of the RF classifier was further assessed with two statistical tests for classification accuracy. The out-of-bag (OOB) estimate of error highlighted the prediction error of RF for each plant community (table 5). The best classification accuracy corresponds to OP, with an OOB of $0.2 \%$. RS and TG show the highest classification errors, with an $\mathrm{OOB}$ of and $13 \%$ and $18 \%$ respectively.

Table 5. OOB estimate of error of the RF classifier for each community type

\begin{tabular}{ll}
\hline Community & Class error \\
\hline Reed Swamp (RS) & $13 \%$ \\
Lower Shore (LS) & $2 \%$ \\
Upper Shore (US) & $10 \%$ \\
Open Pioneer (OP) & $0.2 \%$ \\
Tall Grass (TG) & $18 \%$ \\
\hline
\end{tabular}

The importance of the contribution of each predictor variable on the classification performance of RF was assessed by means of the Mean Decreased Accuracy (MDA) and Mean Decreased Gini (MDG) tests. According to the Gini index (fig. 5), the indices with the highest contribution to the RF model are GDI and DATT4, followed by GRDI and SR. The smallest contribution to the model's classification performance are SRRE, NDVIre and MSRRE. Regarding the Mean Decrease in Accuracy, the contribution of GRDI is the highest with a value of $95 \%$. The contributions of GDI and NDVIre are also important with values of $65 \%$ and $63 \%$. According to the MDA, NDVI and SR have the lowest importance, with values of $52 \%$ and $50 \%$ respectively. 

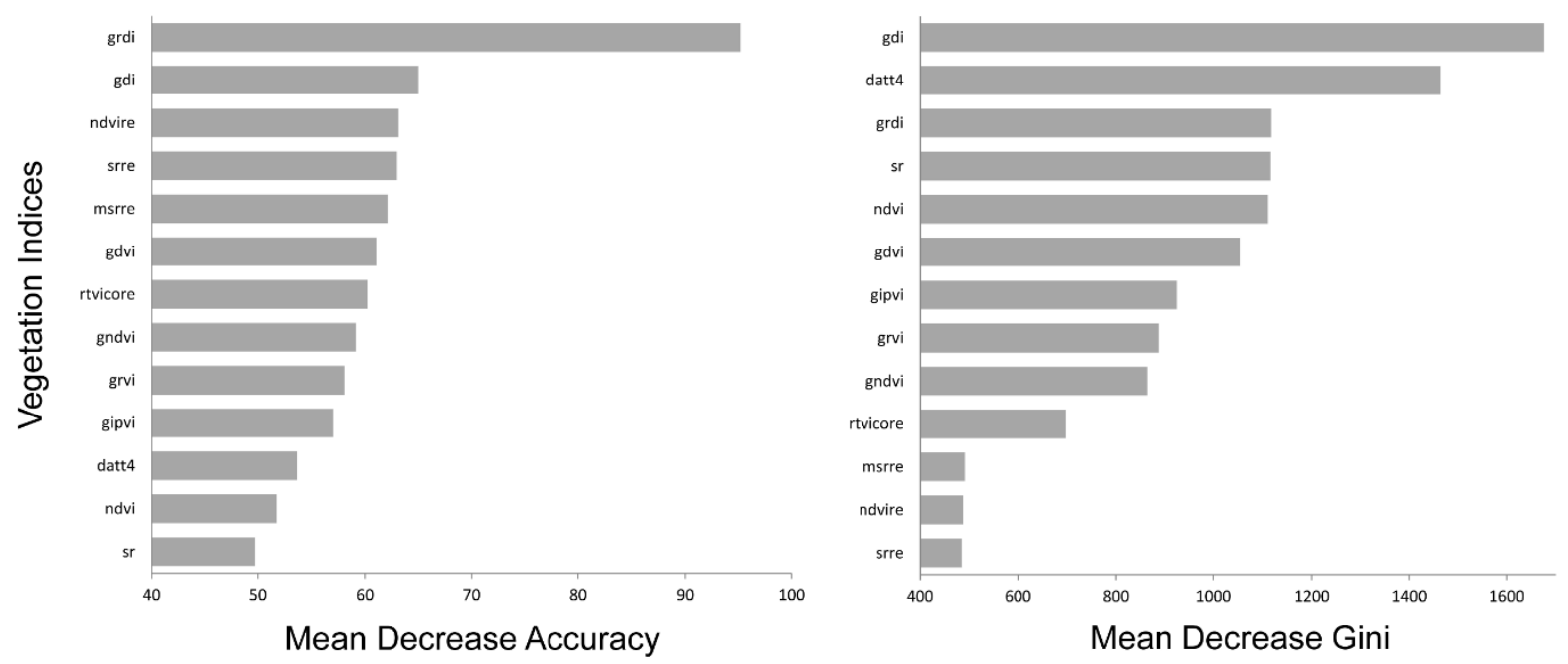

Fig. 5. Mean Decreased Accuracy (MDA) and Mean Decreased Gini (MDG) values for all vegetation indices used as input variables in the RF classifier. Higher MDA and MDG values indicate a higher importance of the input variable in the classification process.

\subsection{PCA for spectral dimension reduction}

433

The best performing combination of input variables in the ISODATA algorithm was the three components of the PCA performed on the vegetation indices and spectral bands. The first three components explain $97 \%$ of the total variance in the multidimensional space (table 6). The first component is highly correlated with ratio-based vegetation indices incorporating the NIR band (NDVI, GNDVI and GIPVI) and a Red-Edge based index (DATT4). The second component is mainly correlated with the individual reflectance bands and two difference-based indices (GDVI and GDI). The third component relates to GRDI and SR.

Table 6. Eigenvectors of the vegetation indices and spectral bands and variance explained by each principal component

\begin{tabular}{llll}
\hline $\begin{array}{l}\text { Vegetation } \\
\text { indices/reflectance } \\
\text { bands }\end{array}$ & $\begin{array}{l}\mathbf{1}^{\text {st }} \text { component }(82.4 \% \\
\text { variance explained) }\end{array}$ & $\begin{array}{l}\mathbf{2}^{\text {nd }} \text { component } \\
\text { variance explained) }\end{array}$ & $\begin{array}{l}\mathbf{3}^{\text {rd }} \text { component } \\
\text { variance explained) }\end{array}$ \\
\hline NDVI & 0.55 & & \\
GIPVI & 0.46 & & \\
GNDVI & 0.46 & & \\
DATT4 & -0.22 & -0.48 & \\
RED-EDGE & & -0.43 & \\
NIR & & -0.42 & \\
GDI & & -0.34 & 0.79 \\
GDVI & -0.26 & 0.24 \\
GREEN & -0.25 & \\
RED & & & \\
GRDI & & \\
SR & & & \\
\hline
\end{tabular}


A graphical comparison of the relationships between spectral diversity and species diversity and biomass is provided in Fig. 6 . Spectral diversity is more sensitive to biomass than to species diversity. Although the relationship between spectral diversity and species diversity is initially positive, it smoothly turns to negative after reaching the highest values of species diversity. It is worth noting that all the plotted points around the negative section of the loess fitted curve (b) correspond to Reed Swamp sampling plots.

(a)

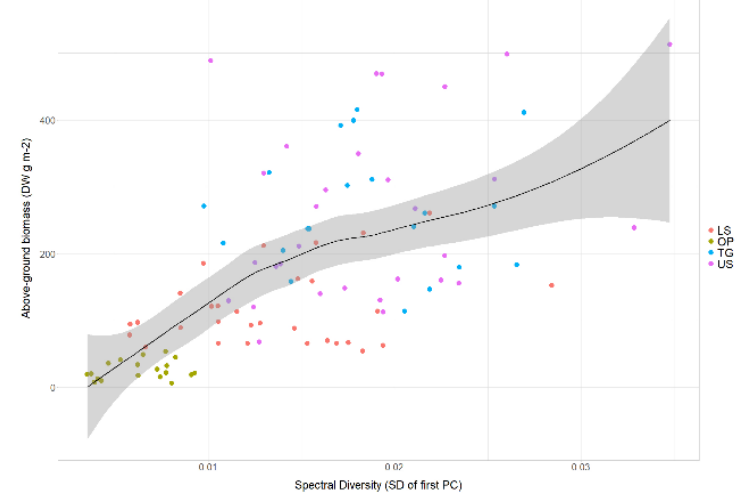

(b)

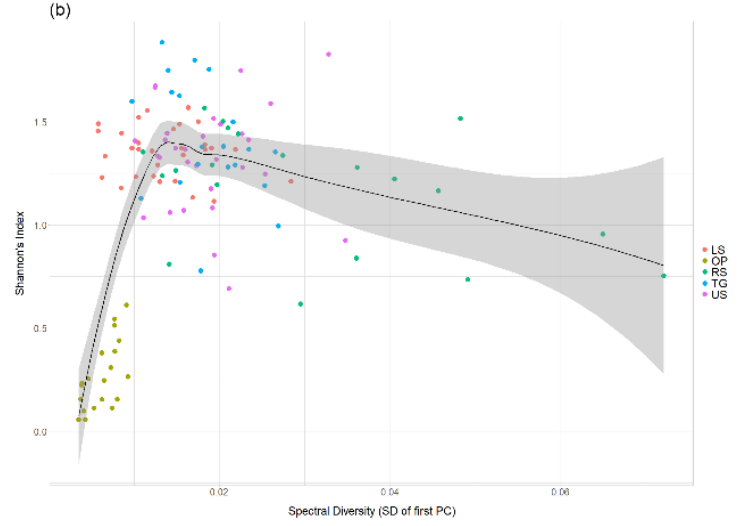

Fig. 6. Relationships between aboveground biomass (a) and Shannon's index (b) vs. spectral diversity. The fitted curves were obtained with a loess smoothing non-linear regression.

\section{DISCUSSION}

The rapid development of UAVs and lightweight sensors in recent years has widened the range of remote sensing applications and solutions (Pajares, 2015). Simultaneously, an unprecedented volume of very high spatial resolution remotely sensed data is being generated, posing a challenge in terms of modelling and interpretation of results (Chi et al., 2016). While the availability of different modelling techniques facilitates the processing of large amounts of remotely sensed data, it is still necessary to understand the modelling capabilities and limitations in order to provide robust results. In this study, a UAV was used to retrieve high-resolution multispectral images of three coastal meadows in West Estonia. Subsequently, a RF model and an ISODATA algorithm were used to map plant communities at the study sites.

The results show that the RF outperforms the ISODATA unsupervised classification algorithm (Table 3). Specifically, the RF algorithm achieved very low per-class OOB errors for Open Pioneer and Lower Shore $(0.2 \%$ and $2 \%$ respectively) and increasingly higher for Upper Shore, Reed Swamp and Tall Grass $(10 \%, 13 \%$ and $18 \%)$. These differences in the classification error between communities can be explained by the spectral characteristics of the vegetation and the training samples. The results of the spectral signature analysis show that in the communities under study, species diversity is slightly correlated with spectral diversity $(r=0.23)$ whereas aboveground biomass is moderately correlated with spectral diversity $(r=0.43)$. This, in turn, has an effect on the characteristics of the training samples and ultimately on the accuracy of the RF algorithm. For instance, low biomass communities such as Lower Shore and communities with a very high proportion of bare ground such as Open Pioneer present a very homogeneous spectral signature. Building upon homogeneous training samples, RF is able to discriminate communities with a high level of precision. On the other hand, a higher aboveground biomass and species diversity results in higher spectral diversity within the training 
samples. This can be observed in the higher classification errors in Upper Shore (higher biomass and diversity than Lower Shore and Open Pioneer), Reed Swamp (highest biomass) and Tall Grass (highest diversity and high biomass).

Plant functional traits and morphological characteristics such as leaf size, branching structure, leaf angle, etc. affect spectral reflectance (Schweiger et al., 2018). In this regard, the spectral diversity hypothesis indicates that species within a community occupy spectral spaces defined by their morphological characteristics (Rocchini et al., 2010a). Consequently, spectral diversity can be used as a proxy for estimating the variability of plant traits within a certain area unit. Similarly, grassland aboveground biomass may have an effect on the spectral variability of remotely sensed images, especially at very high spatial resolutions. Recently grazed grassland patches may show a homogeneous sward structure, especially in terms of sward height and biomass distribution. On the other hand, swards undergoing a period of regrowth are commonly characterized by a complex structure and a higher heterogeneity in both vertical and horizontal dimensions due to individual plants differing in size, growth rates and biomass allocation (Marriott and Carrère, 1998, Wang et al., 2018). Higher biomass swards are therefore expected to show a higher spectral variability. The relationship between species diversity and spectral diversity has been previously studied in the context of biodiversity monitoring, estimation and prediction (Rochinni et al., 2010) and has been tested across a wide variety of habitats and spatial scales, including Mediterranean forests (Rocchini \& Cade, 2008), Amazonian tropical forests (Tuomisto et al., 2003) and African savannas (Rochinni et al., 2010b). In contrast, while many studies focus on the use of multispectral imagery for biomass estimations (Magiera et al., 2017; Punalekar et al., 2018; Naidoo et al., 2019), very few address the relationship between biomass and spectral diversity. The results obtained in this study show that biomass and species diversity have an influence on the characteristics and quality of the training samples. The loess curve shown in Fig. 6a confirms the positive relationship between biomass and spectral diversity described above. However, the relationship between species diversity and spectral diversity shown in Fig. $6 \mathrm{~b}$ suggests a more complex interaction. Increasing levels of species diversity correspond to increased spectral diversity, as has been shown in previous studies. However, after reaching the maximum level of species diversity, the curve turns negative indicating an increase in spectral diversity as Shannon's diversity index decreases. This variation in the relationship can be attributed to two phenomena. On one hand, the sensitivity of spectral diversity to biomass (Fig. 6a) could mask the effect of species diversity. This is indicated by the fact that all the plotted points around the negative section of the loess fitted curve in Fig. $6 \mathrm{~b}$ correspond to Reed Swamp, which is characterized by a high biomass and a relatively low level of species diversity. On the other hand, the very high spatial resolution imagery provided by sensors mounted on UAVs may lead to artefacts. For instance, in communities characterized by tall vegetation such as Reed Swamp, some pixels may fall in areas with direct sunlight while others may fall in shaded areas or gaps between individual plants (Nagendra et al., 2010), therefore increasing the spectral variability of the sample. These results highlight the need to account for the nature and characteristics of spectral diversity when designing and adapting sampling strategies for training plant community classification algorithms.

Regarding the variables importance in the classification accuracy of the RF algorithm, Green Red Difference Index (GRDI) was shown to be the considerably more important than all other indices in classifying plant communities according to the Mean Decreased Accuracy (MDA). The critical role of GRDI in classifying grassland communities is likely to be related to its ability in predicting the percentage of green herbage (Gianelle and Vescovo, 2007). GRDI has also been shown to be sensitive to small changes in leaf colour and leaf density in grasslands (Motohka et al., 2010). Changes in green reflectance captured by GRDI are likely to represent changes in pigment composition between plant species in different communities. 
Based on the classification purity metrics (Mean Decreased Gini), Green Difference Index (GDI) and DATT4 were the most important predictor variables regarding increased data purity after each decision tree node split. These results indicate that GDI and DATT4 show a superior performance to other vegetation indices in terms of obtaining pure classes at the end of the classification process. Similarly to GRDI, GDI may capture changes in green reflectance better than some other indices (e.g. NDVI). DATT4 is a red-edge-based index proposed by Datt (1998) as an alternative to NDVI and GNDVI to maximize the sensitivity to changes in pigment concentration in leaves. A sharp change of reflectance occurs in the red-edge region, related to the transition from chlorophyll absorption to leaf scattering (Delegido et al., 2013). Consequently, the red-edge band has been proven to be very sensitive to variations in chlorophyll $a, b$ and carotenoids (Adamczyk, 2015) and therefore its use in vegetation indices reduces the saturation effect known to affect e.g. NDVI (Clevers and Gitelson, 2013). This explains the key role of DATT4 in the correct classification of plant communities in coastal meadows.

On the other hand, NDVI shows a very low contribution to MDA, which highlights its marginal role in the overall performance of the model. Previous studies suggest NDVI is a poor indicator of forest phenology due to its low sensitivity to leaf colour change (Motohka et al., 2010). In addition, using NDVI can present some limitations due to its sensitivity to the effects of soil brightness, soil colour, atmosphere and leaf canopy shadow (Xue \& Su, 2017) and shows saturation in high density vegetation (Gu et al., 2013). NDVI is therefore likely to also exhibit a low sensitivity to different rates of leaf senescence and proportions of chlorophyll and other pigments in grasslands.

545

546

547

548

549

550

551

552

553

554

555

556

557

558

559

560

561

562

563

564

565

566

567

568

569

570

571

Within this study, an unsupervised classification method was tested in order to compare its performance with the RF algorithm. The ISODATA clustering algorithm reduces costs associated with the training sample collection process. However, the classification accuracy obtained with the different combinations of input variables in ISODATA was considerably lower than RF. The best results were obtained by combining all vegetation indices and individual spectral bands in a PCA (Table 3) and subsequently using the first three components as input variables in the ISODATA clustering algorithm. Mixing individual spectral bands with vegetation indices in the PCA generated a component entirely correlated with the spectral bands (PC2). On the other hand, PC1 incorporated three NIR ratio-based vegetation indices (NDVI, GNDVI and GIPVI) and a Red-Edge based index (DATT4). The highest contribution to $\mathrm{PC2}$ is the red-edge band, which highlights the key role of this band in discerning vegetation types. The clear separation between indices and bands in different components is likely due to the fact that non-normalized spectral bands tend to be correlated among themselves. In fact, the only vegetation indices included in PC2 are non-normalized and also likely correlated with the spectral bands. In previous studies, PCA has been used to compute synthetic bands that are subsequently utilized as input variables in supervised classification algorithms (Yesilnacar \& Süzen, 2006; Novelli et al., 2016) with high classification accuracies. The results in this study highlight that the classes obtained in unsupervised classification do not necessarily correspond to different plant communities on the ground. Nevertheless, these methods provide a good overview of spectral differences over the whole dataset.

Fleiss kappa comparisons between plant community classification techniques offer a quick and simple way to assess classification accuracy (Landis \& Koch, 1977; Chmura Kraemer, 1980). However, Fleiss kappa fails to provide information on the spatial nature of the agreement and disagreement between classification techniques (Gómez \& Montero, 2011). This information is essential, as it helps identify communities characterized by very high spectral heterogeneity due to factors such as disturbance or communities located within or adjacent to ecotones. An assessment of classification disagreement was performed by overlying the RF map with the ISODATA (PCA on bands plus indices) map. The results show that at the study sites, some areas of disagreement correspond to disturbed communities such 
as a recently restored patch of grassland in the western section of Tahu $\mathrm{N}$ or certain sections in Kudani over-trampled by cattle. Similarly, transition areas between Reed Swamp, Tall Grass and Upper Shore show disagreement in the three study sites, perhaps due to structural differences in these ecotones. In addition to the visual interpretation, a kappa map comparison analysis was performed in order to gain a deeper understanding of the characteristics of disagreement between classifications. Generally, the most productive communities (Reed Swamp, Tall Grass and Upper Shore) show the lowest degree of agreement in all three sites, with very low values of $\mathrm{K}_{\text {location, }}$ especially at Tahu N. Although values of $K_{\text {histo }}$ are moderate for these communities, low $K_{\text {location }}$ indicates incorrectly predicted community locations from the ISODATA algorithm. This is most likely due to the presence of large sections of disturbed and transitional communities and the spectral heterogeneity of communities characterized by higher biomass production such as Tall Grass and Reed Swamp.

This study demonstrates the feasibility of using vegetation indices derived from UAV imagery for the classification of plant communities in coastal meadows. The RF model accurately predicted the occurrence of plant communities with a very high kappa value. Previous studies have used similar approaches to discern and map spectrally distant land cover classes such as forest and meadows (Feng et al., 2015; Ahmed et al., 2017) or distinguish crop types (Lottes et al., 2017; Böhler et al., 2018). However, few studies have attempted to map spectrally similar landscape patches at the plant community scale (Strong et al., 2017, Rapinel et al., 2019). The results obtained in this study highlight the need to consider a wide range of vegetation indices in order to achieve the best differentiation between plant communities. Moreover, few studies have attempted to assess the spectral nature of training samples in relation to community structure and composition (Goodwin et al., 2005). Beyond the number of training samples, training polygon size and image resolution, the spectral heterogeneity within the training samples has an impact on the accuracy of the classifications obtained from supervised algorithms. Training datasets with a higher spectral diversity may reduce the ability of machine learning algorithms to discriminate between different plant communities. This study demonstrates the need to assess the spectral characteristics of training samples in order to gain a full understanding of the performance of classification algorithms.

\section{CONCLUSIONS}

Multispectral UAV imagery was successfully used to classify five plant community types in high biodiversity value coastal meadows in West Estonia. The results demonstrate that an appropriate sampling strategy and choice of vegetation indices yield accurate plant community maps. While UAV multispectral imagery in combination with classification algorithms constitute a valuable tool in habitat management and nature conservation contexts, there are several important areas that require attention. Species diversity and biomass heavily influence the spectral characteristics and quality of training samples at different plant communities. This should be accounted for in the design phase of the sample collection process in order to achieve the best classification accuracies. Moreover, it is crucial to utilize a wide array of vegetation indices in order to avoid poor results associated with less sensitive indices such as NDVI. In this regard, the use of the red-edge band delivers good results due to its sensitivity to chlorophylls, carotenoids and other pigments. This study has provided a novel method for mapping grasslands at a plant community level using plant species and biomass data together with random forest modelling utilising a range of different vegetation indices. Future research should further address the optimization of training sample acquisition, modelling algorithms and sample spectral characteristics. 
This work was supported by institutional research funding IUT21-1 at the Estonian Ministry of

1. Aasen, H., Burkart, A., Bolten, A., \& Bareth, G. (2015). Generating 3D hyperspectral information with lightweight UAV snapshot cameras for vegetation monitoring: From camera calibration to quality assurance. ISPRS Journal of Photogrammetry and Remote Sensing,108, 245-259. doi:10.1016/j.isprsjprs.2015.08.002

2. Adamczyk, J., \& Osberger, A. (2015). Red-edge vegetation indices for detecting and assessing disturbances in Norway spruce dominated mountain forests. International Journal of Applied Earth Observation and Geoinformation,37, 90-99. doi:10.1016/j.jag.2014.10.013

3. Adão, T., Hruška, J., Pádua, L., Bessa, J., Peres, E., Morais, R., \& Sousa, J. (2017). Hyperspectral Imaging: A Review on UAV-Based Sensors, Data Processing and Applications for Agriculture and Forestry. Remote Sensing,9(11), 1110. doi:10.3390/rs9111110

4. Ahmed, O. S., Shemrock, A., Chabot, D., Dillon, C., Williams, G., Wasson, R., \& Franklin, S. E. (2017). Hierarchical land cover and vegetation classification using multispectral data acquired from an unmanned aerial vehicle. International Journal of Remote Sensing,38(8-10), 20372052. doi:10.1080/01431161.2017.1294781

5. Armitage, A. R., Highfield, W. E., Brody, S. D., \& Louchouarn, P. (2015). The Contribution of Mangrove Expansion to Salt Marsh Loss on the Texas Gulf Coast. Plos One,10(5). doi:10.1371/journal.pone.0125404

6. Baena, S., Boyd, D. S., \& Moat, J. (2018). UAVs in pursuit of plant conservation - Real world experiences. Ecological Informatics,47, 2-9. doi:10.1016/j.ecoinf.2017.11.001

7. Balzarolo, M., Arriga, N., \& Papale, D. (2009, April). LAl estimation in a Mediterranean grassland by in situ radiometric measurements and MODIS satellite data. In EGU General Assembly Conference Abstracts (Vol. 11, p. 9216).

8. Belgiu, M., \& Drăguţ, L. (2016). Random forest in remote sensing: A review of applications and future directions. ISPRS Journal of Photogrammetry and Remote Sensing,114, 24-31. doi:10.1016/j.isprsjprs.2016.01.011

9. Benkert, D. (2008). Ellenberg, Heinz, Zeigerwerte der Gefäßpflanzen Mitteleuropas. 2. Aufl. Scripta Geobotanica IX. 122 S. Erich Goltze KG. Göttingen, 1979. Kartoniert, DM 21. Feddes Repertorium,91(4), 268-269. doi:10.1002/fedr.19800910408

10. Berg, M., Joyce, C., \& Burnside, N. (2011). Differential responses of abandoned wet grassland plant communities to reinstated cutting management. Hydrobiologia,692(1), 83-97. doi:10.1007/s10750-011-0826-x

11. Berni, J., Zarco-Tejada, P., Suarez, L., \& Fereres, E. (2009). Thermal and Narrowband Multispectral Remote Sensing for Vegetation Monitoring From an Unmanned Aerial Vehicle. IEEE Transactions on Geoscience and Remote Sensing,47(3), 722-738. doi:10.1109/tgrs.2008.2010457

12. Bivand, R., Keitt, T., Rowlingson, B., Pebesma, E., Sumner, M., Hijmans, R., ... \& Bivand, M. R. (2015). Package 'rgdal'. Bindings for the Geospatial Data Abstraction Library. Available online: https://cran. r-project. org/web/packages/rgdal/index. html (accessed on 15 October 2017).

13. Blaschke, T. (2010). Object based image analysis for remote sensing. ISPRS Journal of Photogrammetry and Remote Sensing, 65(1), 2-16. doi: 10.1016/j.isprsjprs.2009.06.004

14. Breiman, L. (2001). Random forests. Machine learning, 45(1), 5-32. doi: 10.1023/A:1010933404324 
15. Brotherton, S. J., \& Joyce, C. B. (2014). Extreme climate events and wet grasslands: Plant traits for ecological resilience. Hydrobiologia, 750(1), 229-243. doi:10.1007/s10750-014-21295

16. Brown, M., Pinzon, J., Didan, K., Morisette, J., \& Tucker, C. (2006). Evaluation of the consistency of long-term NDVI time series derived from AVHRR,SPOT-vegetation, SeaWiFS, MODIS, and Landsat ETM sensors. IEEE Transactions on Geoscience and Remote Sensing,44(7), 1787-1793. doi:10.1109/tgrs.2005.860205

17. Burkhard, B., \& Maes, J. (2017). Mapping ecosystem services. Advanced Books, 1, e12837

18. Burnside, N. G., Joyce, C. B., Puurmann, E., \& Scott, D. M. (2007). Use of vegetation classification and plant indicators to assess grazing abandonment in Estonian coastal wetlands. Journal of Vegetation Science,18(5), 645. doi:10.1658/11009233(2007)18[645:uovcap]2.0.co;2

19. Burnside, N. and Waite, S. (2011) Predictive modelling of biogeographical phenomena. In: Millington, A., Blumler, M. and Schikhoff, U. The SAGE handbook of biogeography. SAGE Publications Ltd. UK.

20. Böhler, J., Schaepman, M., \& Kneubühler, M. (2018). Crop Classification in a Heterogeneous Arable Landscape Using Uncalibrated UAV Data. Remote Sensing,10(8), 1282. doi:10.3390/rs10081282

21. Candiago, S., Remondino, F., Giglio, M. D., Dubbini, M., \& Gattelli, M. (2015). Evaluating Multispectral Images and Vegetation Indices for Precision Farming Applications from UAV Images. Remote Sensing,7(4), 4026-4047. doi:10.3390/rs70404026

22. Cardinale, B. J., Duffy, J. E., Gonzalez, A., Hooper, D. U., Perrings, C., Venail, P., . . Naeem, S. (2012). Biodiversity loss and its impact on humanity. Nature,486(7401), 59-67. doi:10.1038/nature11148

23. Cavender-Bares, J., Gamon, J. A., Hobbie, S. E., Madritch, M. D., Meireles, J. E., Schweiger, A. K., \& Townsend, P. A. (2017). Harnessing plant spectra to integrate the biodiversity sciences across biological and spatial scales. American Journal of Botany,104(7), 966-969. doi:10.3732/ajb.1700061

24. Chen, D., \& Stow, D. (2002). The effect of training strategies on supervised classification at different spatial resolutions. Photogrammetric Engineering and Remote Sensing, 68(11), 1155-1162.

25. Chi, M., Plaza, A., Benediktsson, J. A., Sun, Z., Shen, J., \& Zhu, Y. (2016). Big Data for Remote Sensing: Challenges and Opportunities. Proceedings of the IEEE,104(11), 2207-2219. doi:10.1109/jproc.2016.2598228

26. Chmura Kraemer, H. (1980). Extension of the Kappa Coefficient. Biometrics, 36(2), 207. doi: $10.2307 / 2529972$

27. Clausen, K. K., Stjernholm, M., \& Clausen, P. (2013). Grazing management can counteract the impacts of climate change-induced sea level rise on salt marsh-dependent waterbirds. Journal of Applied Ecology,50(2), 528-537. doi:10.1111/1365-2664.12043

28. Cleveland, W. S., \& Devlin, S. J. (1988). Locally weighted regression: an approach to regression analysis by local fitting. Journal of the American statistical association, 83(403), 596-610.

29. Clevers, J., \& Gitelson, A. (2013). Remote estimation of crop and grass chlorophyll and nitrogen content using red-edge bands on Sentinel-2 and -3. International Journal of Applied Earth Observation and Geoinformation,23, 344-351. doi:10.1016/j.jag.2012.10.008

30. Cook, K. L. (2017). An evaluation of the effectiveness of low-cost UAVs and structure from motion for geomorphic change detection. Geomorphology,278, 195-208. doi:10.1016/j.geomorph.2016.11.009

31. Crawley, M. J. (Ed.). (1997) Plant ecology. Blackwell Publishing Ltd.http://dx.doi.org/10.1002/9781444313642

32. Crippen, R. (1990). Calculating the vegetation index faster. Remote Sensing of Environment,34(1), 71-73. doi:10.1016/0034-4257(90)90085-z 
33. Crossman, N. D., Burkhard, B., Nedkov, S., Willemen, L., Petz, K., Palomo, I., . . Maes, J. (2013). A blueprint for mapping and modelling ecosystem services. Ecosystem Services, 4, 414. doi:10.1016/j.ecoser.2013.02.001

34. Datt, B. (1998). Remote Sensing of Chlorophyll a, Chlorophyll b, Chlorophyll a b, and Total Carotenoid Content in Eucalyptus Leaves. Remote Sensing of Environment,66(2), 111-121. doi:10.1016/s0034-4257(98)00046-7

35. Davidson, S., Santos, M., Sloan, V., Watts, J., Phoenix, G., Oechel, W., \& Zona, D. (2016). Mapping Arctic Tundra Vegetation Communities Using Field Spectroscopy and Multispectral Satellite Data in North Alaska, USA. Remote Sensing,8(12), 978. doi:10.3390/rs8120978

36. Delegido, J., Verrelst, J., Meza, C., Rivera, J., Alonso, L., \& Moreno, J. (2013). A red-edge spectral index for remote sensing estimation of green LAl over agroecosystems. European Journal of Agronomy,46, 42-52. doi:10.1016/j.eja.2012.12.001

37. Diekmann, M. (2003). Species indicator values as an important tool in applied plant ecology a review. Basic and Applied Ecology,4(6), 493-506. doi:10.1078/1439-1791-00185

38. Dietterich, T. G. (2000). An experimental comparison of three methods for constructing ensembles of decision trees: Bagging, boosting, and randomization. Machine learning, 40(2), 139-157. doi: 10.1023/A:1007607513941

39. Dimitriadou, E., Hornik, K., Leisch, F., Meyer, D., Weingessel, A., \& Leisch, M. F. (2006). The e1071 package. Misc Functions of Department of Statistics (e1071), TU Wien.

40. Duda, T., \& Canty, M. (2002). Unsupervised classification of satellite imagery: Choosing a good algorithm. International Journal of Remote Sensing,23(11), 2193-2212. doi:10.1080/01431160110078467

41. EFN and RDSNC. (2001). The inventory of semi-natural grasslands in Estonia 1999-2001: Final report. Estonian Fund for Nature and Royal Dutch Society for Nature Conservation, Estonia.

42. Ellenberg, H. (1979) Zeigerwerte der Gefasspflanzen Mitteleuropas. Scripta Geobotanica 9: 42-111.

43. Everitt, J. H., Yang, C., \& Deloach, C. J. (2005). Remote sensing of giant reed with QuickBird satellite imagery. Journal of Aquatic Plant Management, 43, 81-85.

44. Feng, Q., Liu, J., \& Gong, J. (2015). UAV Remote Sensing for Urban Vegetation Mapping Using Random Forest and Texture Analysis. Remote Sensing,7(1), 1074-1094. doi:10.3390/rs70101074

45. Forsmoo, J., Anderson, K., Macleod, C. J., Wilkinson, M. E., \& Brazier, R. (2018). Drone-based structure-from-motion photogrammetry captures grassland sward height variability. Journal of Applied Ecology,55(6), 2587-2599. doi:10.1111/1365-2664.13148

46. Gianelle, D., \& Vescovo, L. (2007). Determination of green herbage ratio in grasslands using spectral reflectance. Methods and ground measurements. International Journal of Remote Sensng,28(5), 931-942. doi:10.1080/01431160500196398

47. Gislason, P. O., Benediktsson, J. A., \& Sveinsson, J. R. (2006). Random Forests for land cover classification. Pattern Recognition Letters,27(4), 294-300. doi:10.1016/j.patrec.2005.08.011

48. Gitelson, A. A., Kaufman, Y. J., \& Merzlyak, M. N. (1996). Use of a green channel in remote sensing of global vegetation from EOS-MODIS. Remote Sensing of Environment,58(3), 289298. doi:10.1016/s0034-4257(96)00072-7

49. Gitelson, A., \& Merzlyak, M. N. (1994). Spectral Reflectance Changes Associated with Autumn Senescence of Aesculus hippocastanum L. and Acer platanoides L. Leaves. Spectral Features and Relation to Chlorophyll Estimation. Journal of Plant Physiology,143(3), 286-292. doi:10.1016/s0176-1617(11)81633-0

50. Gomez, D., \& Montero, J. (2011). Determining the accuracy in image supervised classification problems. Proceedings of the 7th Conference of the European Society for Fuzzy Logic and Technology (EUSFLAT-2011). doi:10.2991/eusflat.2011.103

51. Gonçalves, J., Henriques, R., Alves, P., Sousa-Silva, R., Monteiro, A. T., Lomba, Â, . . Honrado, J. (2015). Evaluating an unmanned aerial vehicle-based approach for assessing habitat extent 
and condition in fine-scale early successional mountain mosaics. Applied Vegetation Science,19(1), 132-146. doi:10.1111/avsc.12204

52. Goodwin, N., Turner, R., \& Merton, R. (2005). Classifying Eucalyptus forests with high spatial and spectral resolution imagery: An investigation of individual species and vegetation communities. Australian Journal of Botany, 53(4), 337. doi:10.1071/bt04085

53. Gu, Y., Wylie, B. K., Howard, D. M., Phuyal, K. P., \& Ji, L. (2013). NDVI saturation adjustment: A new approach for improving cropland performance estimates in the Greater Platte River Basin, USA. Ecological Indicators,30, 1-6. doi:10.1016/j.ecolind.2013.01.041

54. Hagen, A. (2002, April). Multi-method assessment of map similarity. In Proceedings of the 5th AGILE Conference on Geographic Information Science (pp. 171-182). Palma, Spain: Universitat de les Illes Balears

55. Hamada, Y., Stow, D. A., \& Roberts, D. A. (2011). Estimating life-form cover fractions in California sage scrub communities using multispectral remote sensing. Remote Sensing of Environment,115(12), 3056-3068. doi:10.1016/j.rse.2011.06.008

56. Han, H., Guo, X., \& Yu, H. (2016). Variable selection using Mean Decrease Accuracy and Mean Decrease Gini based on Random Forest. 2016 7th IEEE International Conference on Software Engineering and Service Science (ICSESS). doi:10.1109/icsess.2016.7883053

57. Henle, K., Alard, D., Clitherow, J., Cobb, P., Firbank, L., Kull, T., ... Young, J. (2008). Identifying and managing the conflicts between agriculture and biodiversity conservation in Europe-A review. Agriculture, Ecosystems \& Environment,124(1-2), 60-71. doi:10.1016/j.agee.2007.09.005

58. Hijmans, R. J. \& van Etten, J. (2012). raster: Geographic analysis and modeling with raster data. R package version 2.0-12. http://CRAN.R-project.org/package=raster

59. Houborg, R., \& Mccabe, M. (2016). High-Resolution NDVI from Planet's Constellation of Earth Observing Nano-Satellites: A New Data Source for Precision Agriculture. Remote Sensing,8(9), 768. doi:10.3390/rs8090768

60. Ingerpuu, N., \& Sarv, M. (2015). Effect of Grazing on Plant Diversity of Coastal Meadows in Estonia. Annales Botanici Fennici,52(1-2), 84-92. doi:10.5735/085.052.0210

61. IPCC. (2013). Climate change 2013: Synthesis Report. Cambridge University Press, UK.

62. Jensen, J. R. (2007). Remote sensing of the environment: An earth resource perspective. Upper Saddle River, NJ: Prentice-Hall International.

63. Jones, H. G., \& Vaughan, R. A. (2010). Remote sensing of vegetation: principles, techniques, and applications. Oxford university press..

64. Jordan, C. F. (1969). Derivation of Leaf-Area Index from Quality of Light on the Forest Floor. Ecology,50(4), 663-666. doi:10.2307/1936256

65. Joyce, C. B. (2014). Ecological consequences and restoration potential of abandoned wet grasslands. Ecological Engineering,66, 91-102. doi:10.1016/j.ecoleng.2013.05.008

66. Joyce, C. B., Simpson, M., \& Casanova, M. (2016). Future wet grasslands: Ecological implications of climate change. Ecosystem Health and Sustainability,2(9). doi:10.1002/ehs2.1240

67. Jones, H. \& Vaughan, R. (2010) Remote Sensing of Vegetation Principle Techniques and Applications. Oxford University Press, UK.

68. Keskkonnaamet (2017) Silma looduskaitseala ja Karjatsimere hoiuala kaitsekorralduskava 2017-2026

69. Kuhn, M. (2012). The caret package. R Foundation for Statistical Computing, Vienna, Austria. URL https://cran. r-project. org/package= caret.

70. Landis, J. R., \& Koch, G. G. (1977). The Measurement of Observer Agreement for Categorical Data. Biometrics, 33(1), 159. doi:10.2307/2529310

71. Leito, A., Elts, J., Mägi, E., Ivask, I., Ööpik, M., Sepp, K. \& Ward, R.D. (2014) Coastal grassland wader abundance in relation to breeding habitat characteristics and prey abundance in Matsalu, Estonia. Ornis Fennica 91, 149-165. 
72. Liaw, A. \& Wiener, M. (2002). Classification and Regression by randomForest. R News 2(3), 18--22.

73. Liu, D., \& Xia, F. (2010). Assessing object-based classification: advantages and limitations. Remote Sensing Letters, 1(4), 187-194.

74. Lottes, P., Khanna, R., Pfeifer, J., Siegwart, R., \& Stachniss, C. (2017). UAV-based crop and weed classification for smart farming. 2017 IEEE International Conference on Robotics and Automation (ICRA). doi:10.1109/icra.2017.7989347

75. Lu, B., \& He, Y. (2017). Species classification using Unmanned Aerial Vehicle (UAV)-acquired high spatial resolution imagery in a heterogeneous grassland. ISPRS Journal of Photogrammetry and Remote Sensing,128, 73-85. doi:10.1016/j.isprsjprs.2017.03.011

76. Mafi-Gholami, D., Zenner, E. K., Jaafari, A., \& Ward, R. D. (2019). Modeling multi-decadal mangrove leaf area index in response to drought along the semi-arid southern coasts of Iran. Science of The Total Environment, 656, 1326-1336. doi:10.1016/j.scitotenv.2018.11.462

77. Marriott, C. A., \& Carrère, P. (1998). Structure and dynamics of grazed vegetation. Annales De Zootechnie,47(5-6), 359-369. doi:10.1051/animres:19980504

78. Medina, O., Manian, V., \& Chinea, J. (2013). Biodiversity Assessment Using Hierarchical Agglomerative Clustering and Spectral Unmixing over Hyperspectral Images. Sensors, 13(10), 13949-13959. doi:10.3390/s131013949

79. Memarsadeghi, N., Mount, D. M., Netanyahu, N. S., \& Moigne, J. L. (2007). A Fast Implementation Of The Isodata Clustering Algorithm. International Journal of Computational Geometry \& Applications,17(01), 71-103. doi:10.1142/s0218195907002252

80. Motohka, T., Nasahara, K. N., Oguma, H., \& Tsuchida, S. (2010). Applicability of Green-Red Vegetation Index for Remote Sensing of Vegetation Phenology. Remote Sensing,2(10), 23692387. doi:10.3390/rs2102369

81. Mueller-Dombois, D., \& Ellenberg, H. (1974). Aims and methods of vegetation ecology. Wiley

82. Nagendra, H., Rocchini, D., Ghate, R., Sharma, B., \& Pareeth, S. (2010). Assessing Plant Diversity in a Dry Tropical Forest: Comparing the Utility of Landsat and Ikonos Satellite Images. Remote Sensing, 2(2), 478-496. doi: 10.3390/rs2020478

83. Naidoo, L., Deventer, H. V., Ramoelo, A., Mathieu, R., Nondlazi, B., \& Gangat, R. (2019). Estimating above ground biomass as an indicator of carbon storage in vegetated wetlands of the grassland biome of South Africa. International Journal of Applied Earth Observation and Geoinformation,78, 118-129. doi:10.1016/j.jag.2019.01.021

84. Navarro, G., Caballero, I., Silva, G., Parra, P., Vázquez, Á, \& Caldeira, R. (2017). Evaluation of forest fire on Madeira Island using Sentinel-2A MSI imagery. International Journal of Applied Earth Observation and Geoinformation,58, 97-106. doi:10.1016/j.jag.2017.02.003

85. Newbold, T., Hudson, L. N., Arnell, A. P., Contu, S., Palma, A. D., Ferrier, S., . . Purvis, A. (2016). Has land use pushed terrestrial biodiversity beyond the planetary boundary? A global assessment. Science,353(6296), 288-291. doi:10.1126/science.aaf2201

86. Novelli, A., Tarantino, E., Caradonna, G., Apollonio, C., Balacco, G., \& Piccinni, F. (2016). Improving the ANN Classification Accuracy of Landsat Data Through Spectral Indices and Linear Transformations (PCA and TCT) Aimed at LU/LC Monitoring of a River Basin. Computational Science and Its Applications - ICCSA 2016 Lecture Notes in Computer Science, 420-432. doi:10.1007/978-3-319-42108-7_32

87. Oldeland, J., Wesuls, D., Rocchini, D., Schmidt, M., \& Jürgens, N. (2010). Does using species abundance data improve estimates of species diversity from remotely sensed spectral heterogeneity? Ecological Indicators,10(2), 390-396. doi:10.1016/j.ecolind.2009.07.012

88. Paal, J. (1998). Rare and threatened plant communities of Estonia. Biodiversity \& Conservation, 7(8), 1027-1049.Pajares, G. (2015). Overview and Current Status of Remote Sensing Applications Based on Unmanned Aerial Vehicles (UAVs). Photogrammetric Engineering \& Remote Sensing,81(4), 281-330. doi:10.14358/pers.81.4.281 
89. Pajares, G. (2015). Overview and Current Status of Remote Sensing Applications Based on Unmanned Aerial Vehicles (UAVs). Photogrammetric Engineering \& Remote Sensing, 81(4), 281-330. doi:10.14358/pers.81.4.281

90. Pontius, R. G. (2001). Quantification error versus location error in comparison of categorical maps (vol 66, pg 1011, 2000). Photogrammetric Engineering and Remote Sensing, 67(5), 540540

91. Pontius, R. G. (2002). Statistical methods to partition effects of quantity and location during comparison of categorical maps at multiple resolutions. Photogrammetric Engineering and Remote Sensing, 68(10), 1041-1050.

92. Punalekar, S., Verhoef, A., Quaife, T., Humphries, D., Bermingham, L., \& Reynolds, C. (2018). Application of Sentinel-2A data for pasture biomass monitoring using a physically based radiative transfer model. Remote Sensing of Environment,218, 207-220. doi:10.1016/j.rse.2018.09.028

93. Punalekar, S., Verhoef, A., Quaife, T., Humphries, D., Bermingham, L., \& Reynolds, C. (2018). Application of Sentinel-2A data for pasture biomass monitoring using a physically based radiative transfer model. Remote Sensing of Environment, 218, 207-220. doi:10.1016/j.rse.2018.09.028

94. Rapinel, S., Mony, C., Lecoq, L., Clément, B., Thomas, A., \& Hubert-Moy, L. (2019). Evaluation of Sentinel-2 time-series for mapping floodplain grassland plant communities. Remote Sensing of Environment,223, 115-129. doi:10.1016/j.rse.2019.01.018

95. Rasmussen, J., Ntakos, G., Nielsen, J., Svensgaard, J., Poulsen, R. N., \& Christensen, S. (2016). Are vegetation indices derived from consumer-grade cameras mounted on UAVs sufficiently reliable for assessing experimental plots? European Journal of Agronomy,74, 75-92. doi:10.1016/j.eja.2015.11.026

96. Robinson, N., Allred, B., Jones, M., Moreno, A., Kimball, J., Naugle, D., . . Richardson, A. (2017). A Dynamic Landsat Derived Normalized Difference Vegetation Index (NDVI) Product for the Conterminous United States. Remote Sensing,9(8), 863. doi:10.3390/rs9080863

97. Rocchini, D., \& Cade, B. S. (2008). Quantile Regression Applied to Spectral Distance Decay. IEEE Geoscience and Remote Sensing Letters,5(4), 640-643. doi:10.1109/Igrs.2008.2001767

98. Rocchini, D., Balkenhol, N., Carter, G. A., Foody, G. M., Gillespie, T. W., He, K. S., . .. Neteler, M. (2010a). Remotely sensed spectral heterogeneity as a proxy of species diversity: Recent advances and open challenges. Ecological Informatics,5(5), 318-329. doi:10.1016/j.ecoinf.2010.06.001

99. Rocchini, D., Boyd, D. S., Féret, J., Foody, G. M., He, K. S., Lausch, A., . . Pettorelli, N. (2015). Satellite remote sensing to monitor species diversity: Potential and pitfalls. Remote Sensing in Ecology and Conservation,2(1), 25-36. doi:10.1002/rse2.9

100. Rocchini, D., Chiarucci, A., \& Loiselle, S. A. (2004). Testing the spectral variation hypothesis by using satellite multispectral images. Acta Oecologica,26(2), 117-120. doi:10.1016/j.actao.2004.03.008

101. Rocchini, D., He, K. S., Oldeland, J., Wesuls, D., \& Neteler, M. (2010b). Spectral variation versus species $\beta$-diversity at different spatial scales: A test in African highland savannas. Journal of Environmental Monitoring,12(4), 825. doi:10.1039/b921835a

102. Rodriguez-Galiano, V., Ghimire, B., Rogan, J., Chica-Olmo, M., \& Rigol-Sanchez, J. (2012). An assessment of the effectiveness of a random forest classifier for land-cover classification. ISPRS Journal of Photogrammetry and Remote Sensing,67, 93-104. doi:10.1016/j.isprsjprs.2011.11.002

103. Rodwell, J. (1992) British Plant Communities. Volumes I-V. Cambridge University Press, UK.

104. Rouse Jr, J., Haas, R. H., Schell, J. A., \& Deering, D. W. (1974). Monitoring vegetation systems in the Great Plains with ERTS. 
105. Schweiger, A. K., Cavender-Bares, J., Townsend, P. A., Hobbie, S. E., Madritch, M. D., Wang, R., ... Gamon, J. A. (2018). Plant spectral diversity integrates functional and phylogenetic components of biodiversity and predicts ecosystem function. Nature Ecology \& Evolution,2(6), 976-982. doi:10.1038/s41559-018-0551-1

106. Schäfer, E., Heiskanen, J., Heikinheimo, V., \& Pellikka, P. (2016). Mapping tree species diversity of a tropical montane forest by unsupervised clustering of airborne imaging spectroscopy data. Ecological Indicators, 64, 49-58. doi:10.1016/j.ecolind.2015.12.026

107. Silveira, H. L., Galvão, L. S., Sanches, I. D., Sá, I. B., \& Taura, T. A. (2018). Use of $\mathrm{MSI} /$ Sentinel-2 and airborne LiDAR data for mapping vegetation and studying the relationships with soil attributes in the Brazilian semi-arid region. International Journal of Applied Earth Observation and Geoinformation,73, 179-190. doi:10.1016/j.jag.2018.06.016

108. Sripada, R. P., Heiniger, R. W., White, J. G., \& Meijer, A. D. (2006). Aerial Color Infrared Photography for Determining Early In-Season Nitrogen Requirements in Corn. Agronomy Journal,98(4), 968. doi:10.2134/agronj2005.0200

109. Strong, C. J., Burnside, N. G., \& Llewellyn, D. (2017). The potential of small-Unmanned Aircraft Systems for the rapid detection of threatened unimproved grassland communities using an Enhanced Normalized Difference Vegetation Index. Plos One,12(10). doi:10.1371/journal.pone.0186193

110. Söderström, B. O., Svensson, B., Vessby, K., \& Glimskär, A. (2001). Plants, insects and birds in semi-natural pastures in relation to local habitat and landscape factors. Biodiversity \& Conservation, 10(11), 1839-1863.

111. Tadrowski, T. (2014). Accurate Mapping using Drones (UAV's). Geolnformatics, 17(8), 18.

112. Tansley, A. (1920) The Classification of Vegetation and the Concept of Development Journal of Ecology 8: 118-149

113. Townsend, P. A., \& Walsh, S. J. (2001). Remote sensing of forested wetlands: application of multitemporal and multispectral satellite imagery to determine plant community composition and structure in southeastern USA. Plant Ecology, 157(2), 129-149.

114. Tuomisto, H., Poulsen, A. D., Ruokolainen, K., Moran, R. C., Quintana, C., Celi, J., \& Cañas, G. (2003). Linking Floristic Patterns With Soil Heterogeneity And Satellite Imagery In Ecuadorian Amazonia. Ecological Applications,13(2), 352-371. doi:10.1890/10510761(2003)013[0352:Ifpwsh]2.0.co;2

115. Turner, D., Lucieer, A., Malenovský, Z., King, D., \& Robinson, S. A. (2018). Assessment of Antarctic moss health from multi-sensor UAS imagery with Random Forest Modelling. International Journal of Applied Earth Observation and Geoinformation, 68, 168179. doi:10.1016/j.jag.2018.01.004

116. Veettil, B. K., Ward, R. D., Quang, N. X., Trang, N. T., \& Giang, T. H. (2019). Mangroves of Vietnam: Historical development, current state of research and future threats. Estuarine, Coastal and Shelf Science,218, 212-236. doi:10.1016/j.ecss.2018.12.021

117. Villoslada, M., Bunce, R. G., Sepp, K., Jongman, R. H., Metzger, M. J., Kull, T., . . Leito, A. (2016). A framework for habitat monitoring and climate change modelling: Construction and validation of the Environmental Stratification of Estonia. Regional Environmental Change,17(2), 335-349. doi:10.1007/s10113-016-1002-7

118. Villoslada, M., Ward, R. D., Bunce, R. G., Sepp, K., Kuusemets, V., \& Luuk, O. (2019). Country-scale mapping of ecosystem services provided by semi-natural grasslands. Science of The Total Environment,661, 212-225. doi:10.1016/j.scitotenv.2019.01.174

119. Visser, H., \& Nijs, T. D. (2006). The Map Comparison Kit. Environmental Modelling \& Software,21(3), 346-358. doi:10.1016/j.envsoft.2004.11.013

120. Wang, R., Gamon, J. A., Cavender-Bares, J., Townsend, P. A., \& Zygielbaum, A. I. (2018). The spatial sensitivity of the spectral diversity-biodiversity relationship: An experimental test in a prairie grassland. Ecological Applications,28(2), 541-556. doi:10.1002/eap.1669 
121. Wang, D., Xin, X., Shao, Q., Brolly, M., Zhu, Z., \& Chen, J. (2017). Modeling Aboveground Biomass in Hulunber Grassland Ecosystem by Using Unmanned Aerial Vehicle Discrete Lidar. Sensors,17(12), 180. doi:10.3390/s17010180

122. Ward, R. (2012). Landscape and ecological modelling: Development of a plant community prediction tool for Estonian coastal wetlands (Doctoral dissertation, University of Brighton).

123. Ward, R. D., Burnside, N. G., Joyce, C. B., \& Sepp, K. (2013). The use of medium point density LiDAR elevation data to determine plant community types in Baltic coastal wetlands. Ecological Indicators,33, 96-104. doi:10.1016/j.ecolind.2012.08.016

124. Ward, R. D., Burnside, N. G., Joyce, C. B., \& Sepp, K. (2016a). Importance of Microtopography in Determining Plant Community Distribution in Baltic Coastal Wetlands. Journal of Coastal Research,321, 1062-1070. doi:10.2112/jcoastres-d-15-00065.1

125. Ward, R. D., Burnside, N. G., Joyce, C. B., Sepp, K., \& Teasdale, P. A. (2016b). Improved modelling of the impacts of sea level rise on coastal wetland plant communities. Hydrobiologia,774(1), 203-216. doi:10.1007/s10750-015-2374-2

126. Ward, R. D., Teasdale, P. A., Burnside, N. G., Joyce, C. B., \& Sepp, K. (2014). Recent rates of sedimentation on irregularly flooded Boreal Baltic coastal wetlands: Responses to recent changes in sea level. Geomorphology,217, 61-72.

doi:10.1016/j.geomorph.2014.03.045

127. Westoby, M., Brasington, J., Glasser, N., Hambrey, M., \& Reynolds, J. (2012). 'Structure-from-Motion' photogrammetry: A low-cost, effective tool for geoscience applications. Geomorphology,179, 300-314. doi:10.1016/j.geomorph.2012.08.021

128. Wu, C., Niu, Z., Tang, Q., \& Huang, W. (2008). Estimating chlorophyll content from hyperspectral vegetation indices: Modeling and validation. Agricultural and Forest Meteorology,148(8-9), 1230-1241. doi:10.1016/j.agrformet.2008.03.005

129. Xie, Q., Dash, J., Huang, W., Peng, D., Qin, Q., Mortimer, H., ... Ye, H. (2018). Vegetation Indices Combining the Red and Red-Edge Spectral Information for Leaf Area Index Retrieval. IEEE Journal of Selected Topics in Applied Earth Observations and Remote Sensing,11(5), 1482-1493. doi:10.1109/jstars.2018.2813281

130. Xue, J., \& Su, B. (2017). Significant Remote Sensing Vegetation Indices: A Review of Developments and Applications. Journal of Sensors, 2017, 1-17. doi:10.1155/2017/1353691

131. Yesilnacar, E., \& Süzen, M. L. (2006). A land-cover classification for landslide susceptibility mapping by using feature components. International Journal of Remote Sensing, 27(2), 253-275. doi:10.1080/0143116050030042

132. Zabalza, J., Ren, J., Yang, M., Zhang, Y., Wang, J., Marshall, S., \& Han, J. (2014). Novel Folded-PCA for improved feature extraction and data reduction with hyperspectral imaging and SAR in remote sensing. ISPRS Journal of Photogrammetry and Remote Sensing,93, 112122. doi:10.1016/j.isprsjprs.2014.04.006

133. Zulian, G., Stange, E., Woods, H., Carvalho, L., Dick, J., Andrews, C., ... Viinikka, A. (2018). Practical application of spatial ecosystem service models to aid decision support. Ecosystem Services,29, 465-480. doi:10.1016/j.ecoser.2017.11.005 